Article

\title{
Preparation and Electrical Properties of $\mathrm{La}_{0.9} \mathrm{Sr}_{0.1} \mathrm{TiO}_{3+\delta}$
}

\section{Wenzhi Li ${ }^{1,2}$, Zhuang Ma ${ }^{1,2}$, Lihong Gao ${ }^{1,2, *}$ and Fuchi Wang ${ }^{1,2}$}

1 School of Material Science and Engineering, Beijing Institute of Technology, Beijing 100081, China; E-Mails: liwenzhi0418@163.com (W.L.); hstrong929@bit.edu.cn (Z.M.); wangfuchi@bit.edu.cn (F.W.)

2 National Key Laboratory of Science and Technology on Materials under Shock and Impact, Beijing 100081, China

* Author to whom correspondence should be addressed; E-Mail: gaolihong@bit.edu.cn; Tel.: +86-10-6891-1144.

Academic Editor: Marco Salerno

Received: 13 December 2014 / Accepted: 9 February 2015 / Published: 17 March 2015

\begin{abstract}
La}_{1-x} \mathrm{Sr}_{x} \mathrm{TiO}_{3+\delta}$ (LST) has been studied in many fields, especially in the field of microelectronics due to its excellent electrical performance. Our previous theoretical simulated work has suggested that LST has good dielectric properties, but there are rare reports about this, especially experimental reports. In this paper, LST was prepared using a solid-state reaction method. The X-rays diffraction (XRD), scanning electron microscope (SEM), broadband dielectric spectroscopy, impedance spectroscopy and photoconductive measurement were used to characterize the sample. The results show that the values of dielectric parameters (the relative dielectric constant $\varepsilon_{\mathrm{r}}$ and dielectric loss tan $\delta$ ), dependent on temperature, are stable under $350{ }^{\circ} \mathrm{C}$ and the value of the relative dielectric constant and dielectric loss are about $52-88$ and $6.5 \times 10^{-3}$, respectively. Its value of conductivity increases with rise in temperature, which suggests its negative temperature coefficient of the resistance. In addition, the band gap of LST is about $3.39 \mathrm{eV}$, so it belongs to a kind of wide-band-gap semiconductor materials. All these indicate that LST has anti-interference ability and good dielectric properties. It could have potential applications as an electronic material.
\end{abstract}

Keywords: $\mathrm{La}_{0.9} \mathrm{Sr}_{0.1} \mathrm{TiO}_{3+\delta}$; dielectric properties; conductivity; band gap 


\section{Introduction}

Ceramic materials have received great attention because of their good stability, heat resistance, component of flexibility and many other excellent physical and chemical properties $[1,2]$. Especially in the field of microelectronics, perovskite ceramic materials with a general chemical formula $\mathrm{ABO}_{3}$ have been extensively used in microcircuit, modules and devices [3]. $\mathrm{LaTiO}_{3}$ and $\mathrm{SrTiO}_{3}$ both are ferroelectric ceramic and it has been reported that they have good dielectric properties, such as high dielectric constant, low dielectric loss and good temperature coefficient, etc. In addition, in recent years, lanthanum-doped and strontium-doped ceramic composite material as a new kind of perovskite ceramic material has been widely researched and used as solid fuel cell anode material, microwave dielectric material and photo-dew-sensitive material, etc. [4-8]. Therefore, it could be supposed that $\mathrm{La}_{1-x} \mathrm{Sr}_{x} \mathrm{TiO}_{3+\delta}$ (LST) may have better properties and potential applications. However, the dielectric and photoelectric properties of bulk LST are currently rarely reported.

The main purpose of this paper is to do a deep research of the dielectric and photoelectric properties of LST. Our previous theoretical simulated work has suggested that $\mathrm{La}_{0.9} \mathrm{Sr}_{0.1} \mathrm{TiO}_{3}+\delta$ has higher dielectric function and refractive index [9]. Our following experimental research has confirmed that $\mathrm{La}_{0.9} \mathrm{Sr}_{0.1} \mathrm{TiO}_{3+\delta}$ has the highest reflectivity $(99 \%$ at $10.6 \mu \mathrm{m})[10]$. So this paper will focus on LST with $x=0.1$, considering the relationship between optical and electrical properties. LST was prepared by high-temperature solid state reaction method. Its phase structure was characterized and its dielectric and photoelectric properties were investigated.

\section{Experiments}

\subsection{Sample Preparation}

The LST samples were prepared by high temperature solid state reaction method using high-purity raw materials: $\mathrm{La}_{2} \mathrm{O}_{3}(99.99 \%), \mathrm{SrCO}_{3}(\mathrm{AR})$ and $\mathrm{TiO}_{2}(\mathrm{AR})$. These raw materials were weighed stoichiometricly and mixed mechanically, then presintered at $1200{ }^{\circ} \mathrm{C}$ for $2 \mathrm{~h}$ in order to reduce the thermal stress during sintering. The presintered powders were mechanically pre-pressed into cylindrical pellets $(10 \mathrm{~mm}$ in diameter and 1-2 mm in thickness) at $8 \mathrm{MPa}$ for $5 \mathrm{~min}$ and then pressed using cold isostatic press at $200 \mathrm{MPa}$ for $5 \mathrm{~min}$. The pellet samples were finally sintered at $1550^{\circ} \mathrm{C}$ for $8 \mathrm{~h}$ in air and followed by furnace cooling. Then we got the white samples. To study the dielectric properties of LST, both the top and bottom surfaces of the sample were coated with platinum electrodes by vacuum sputtering, and then annealed at $150{ }^{\circ} \mathrm{C}$ for $20 \mathrm{~min}$ to reduce the influence of contact resistance during the electric measurements.

\subsection{Characterization}

The phase composition of LST was characterized by X-ray diffraction (PANalytical Inc., X'Pert PRO MPD, Almelo, The Netherlands) with $\mathrm{Cu} \mathrm{K \alpha}$ radiation and analyzed by JADE (version 5.0, Materials Data Inc., Livermore, CA, USA). The surface microstructure of LST was observes by scanning electron microscope (HITACHI S4800, Tokyo, Japan). The dielectric and other related electrical parameters were obtained by broadband dielectric spectroscopy and AC (alternating current) impedance spectroscopy instrument (Novocontrol Technologies Inc., Alpha-A, Montabaur, Germany) 
from the samples coated with platinum electrodes. This impedance spectroscopy instrument performs in a wide frequency range $(0.01 \mathrm{~Hz}-6 \mathrm{MHz})$ at different temperature (room temperature $\sim 700{ }^{\circ} \mathrm{C}$ ). The photoelectric property of LST was measured at room temperature by photoconductive measurement instrument (Keithley Instruments Inc., 4200-SCS, Cleveland, OH, USA) with bare sample.

\section{Result and Discussion}

\subsection{Phase Structure and Surface Microstructure of LST}

Figure 1 shows the XRD pattern of LST. The diffraction peaks are attributed to a single layered perovskite $\mathrm{SrLa}_{8} \mathrm{Ti}_{9} \mathrm{O}_{31}$ phase. It indicates that after sintering at $1650{ }^{\circ} \mathrm{C}$ for $8 \mathrm{~h}$ the raw materials and their intermediate materials could fully react and produce $\mathrm{SrLa}_{8} \mathrm{Ti}_{9} \mathrm{O}_{31}$ single phase. This experimental condition is in accord with Takamura et al.'s research, which obtained $\mathrm{SrLa}_{8} \mathrm{~T}_{19} \mathrm{O}_{31}$ single phase by the Pechiniprocess [11]. By analyzing with Jade we get the lattice parameters are: $a=7.810 \AA, b=5.533 \AA$, $c=57.010 \AA, \alpha=\beta=\gamma=90^{\circ}$, which is consistent with the literatures [12].



Figure 1. XRD pattern of $\mathrm{La}_{0.9} \mathrm{Sr}_{0.1} \mathrm{TiO}_{3}+\delta$.

Figure 2 shows the surface microstructure of LST. There are little visible pores, which make the density of LST is just $4.63 \mathrm{~g} / \mathrm{cm}^{3}$. Moreover, the low porosity of the sample has the benefit of improving its dielectric properties. Banno optimized [13] the formula between porosity and dielectric properties of the material, which indicates that lower porosity and less grain boundary make higher dielectric constant. Therefore, with our previous work [9], we think the dielectric properties of LST, which have layered perovskite structure and higher density, may be improved.

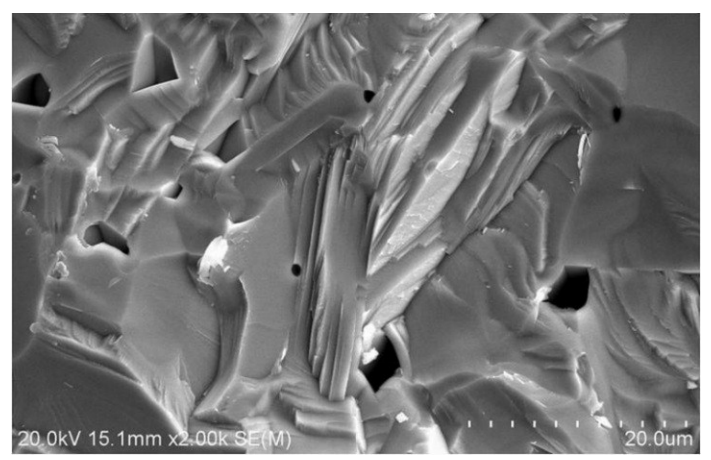

Figure 2. Surface microstructure of $\mathrm{La}_{0.9} \mathrm{Sr}_{0.1} \mathrm{TiO}_{3+\delta}$ by SEM. 


\subsection{Dielectric Properties}

The relative dielectric constant $\left(\varepsilon_{\mathrm{r}}\right)$ and dielectric loss $(\tan \delta)$ of LST as functions of temperature at different frequencies, obtained from broadband dielectric spectroscopy, are shown in Figures 3 and 4. It can be observed that both relative dielectric constant and dielectric loss decrease with increasing frequency, which is a general feature of dielectric materials [14]. The relative dielectric constant and dielectric loss of this material are stable under $350{ }^{\circ} \mathrm{C}$, especially at high frequency, in which $\varepsilon_{\mathrm{r}}$ is between 52 and 88 and $\tan \delta$ can reach $6.5 \times 10^{-3}$. The dielectric properties of LST are improved compared to the reported dielectric constant value of $\mathrm{SrTiO}_{3}$ (about 10 at room temperature) [15].

As shown in Figure 3, Er decreases with increasing frequency, because at the higher frequency lower polarization can be established. $\varepsilon_{\mathrm{r}}$ is almost a constant under $500{ }^{\circ} \mathrm{C}$, which may be due to lower relaxation polarization. A similar phenomenon has been observed in Pati's research [16]. In the high-temperature region $\left(500-650{ }^{\circ} \mathrm{C}\right)$, there is a sharp increase in $\varepsilon$ r. Its higher value may be due to space charge polarization which comes from mobility of ions and defects in the material, which is similar to Abhijit's report [17]. However, in the much higher temperature range $\left(650-700{ }^{\circ} \mathrm{C}\right)$, high temperature makes the heat stimulation more strongly, which causes the ferroelectric domain wall motion become more difficult. Therefore, the polarization state of disorder has become the major influence factor of $\varepsilon_{\mathrm{r}}$ and this fact leads to a sharp decrease in $\varepsilon_{\mathrm{r}}$ with increasing temperature, especially for low frequencies [18]. Tc of LST is thus located in the temperature region of $500-650{ }^{\circ} \mathrm{C}$.



Figure 3. Temperature dependent $\varepsilon_{\mathrm{r}}$ at different frequencies of $\mathrm{La} 0.9 \mathrm{Sr}_{0.1} \mathrm{TiO}_{3}+\delta$.

As shown in Figure 4, the value of $\tan \delta$ increases with increasing temperature (room temperature $\sim 600{ }^{\circ} \mathrm{C}$ ). It's associated to ionic conductivity, which is caused by the loss of oxygen during high-temperature sintering. Thus, this defect plays an important role in the conductivity of LST, which causes the dielectric loss increase [19]. Between 600 and about $680{ }^{\circ} \mathrm{C}$, $\tan \delta$ slightly decreases with increasing temperature, which is due to the decreasing of the relaxation time [16,20]. At higher temperature (about $680-700{ }^{\circ} \mathrm{C}$ ), a sharp increase in $\tan \delta$ is resulted by the scattering of thermally 
activated charge carriers [21] and the presence of some defects such as oxygen vacancies in the sample. In this temperature region, the conductivity becomes the main reason of rise in tan $\delta$. still does not exist in the ferroelectric domain's wall may be another reason [20] as well. Besides, the dielectric loss decreased with the increasing in frequency. It can be explained by the following relationship among dielectric loss, conductivity and frequency [22]:

$$
\tan \delta \propto \frac{\sigma}{\omega}
$$

where $\tan \delta$ is the dielectric loss, $\sigma$ is the conductivity and $\omega$ is the frequency. The increase in the conductivity is smaller than that of frequency. Therefore, the dielectric loss decreased with the increasing in frequency in the whole temperature range.

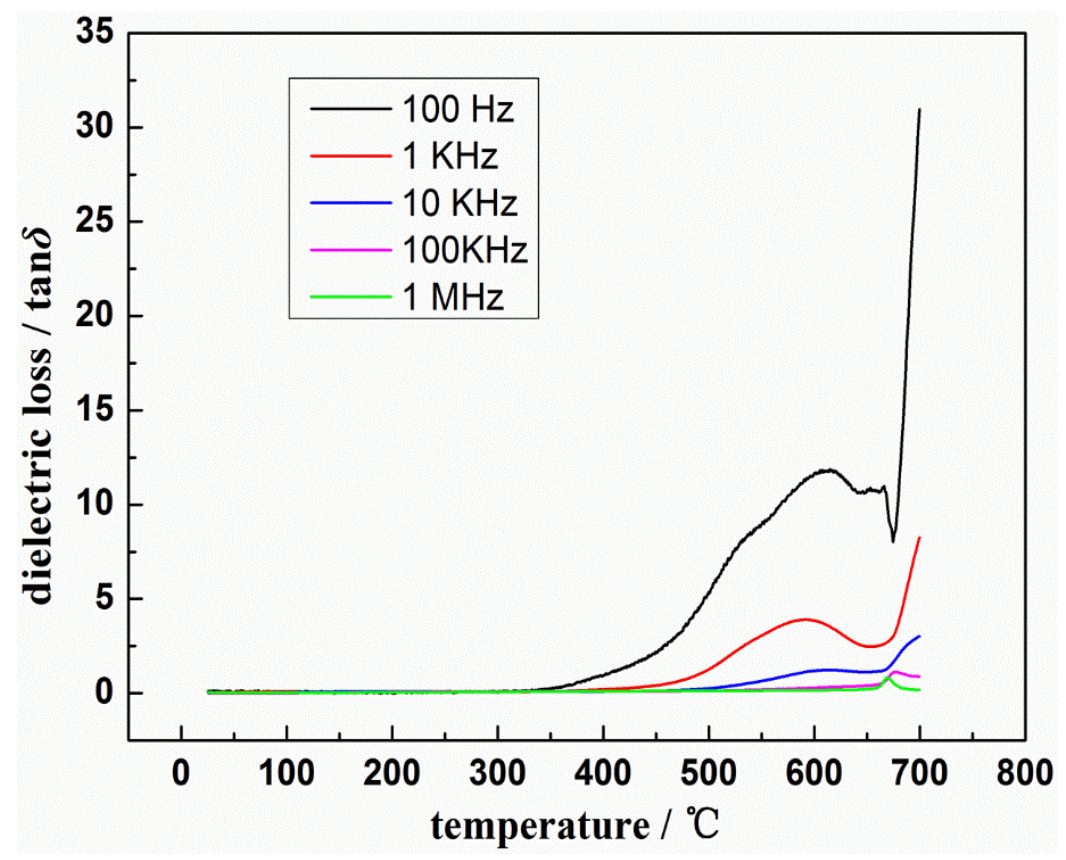

Figure 4. Temperature dependent tan $\delta$ at different frequencies of $\mathrm{La}_{0.9} \mathrm{Sr}_{0.1} \mathrm{TiO}_{3+\delta}$.

\subsection{AC Impedance Spectra Analysis}

The AC complex impedance spectroscopy is a widely used nondestructive technique to investigate the electrical process and conductive mechanism of materials. This technique is very effective to study the contribution of impedance and other related parameters along with the equivalent circuits. In this work, the LST sample coated with platinum electrodes can be regarded as a simple capacitor, the equivalent circuit of which is shown in Figure 5 [23]. Moreover, the equivalent circuit can be summed from a single $R C$ (resistance and capacitance) circuit with parallel combination. So its real part (resistive, $Z_{\mathrm{s}}$ ') and imaginary part (reactive, $Z_{\mathrm{s}}$ ") of complex impedance $\left(Z_{\mathrm{s}}^{*}\right)$ can be calculated using the following basic equation [24]:

$$
Z_{s}{ }^{*}=Z_{s}{ }^{\prime}-j Z_{s}{ }^{\prime \prime}=R_{s}-\left(j / \omega C_{s}\right)
$$

where $\omega$ is the angular frequency, $R_{\mathrm{s}}$ and $C_{\mathrm{s}}$ are resistance and capacitance respectively. 




Figure 5. Complex impedance spectrum equivalent electrical circuit.

Figure 6 shows the complex impedance spectra of LST at different temperature $\left(100-600^{\circ} \mathrm{C}\right)$ over a wide range of frequency $(0.01 \mathrm{~Hz}-6 \mathrm{MHz})$. The impedance of this material is characterized by the formation of semicircular arcs which can mainly be attributed to a parallel combination of resistance and capacitance. According to the equivalent circuit of the sample, the extent of intercept of semicircles on the real axis $\left(Z_{\mathrm{s}}^{\prime}\right)$ provides the value of resistance, which could be used to calculate the conductivity of the sample. But generally, the crossover point between semicircular arcs and the real axis at low frequency may not exist, as shown in Figure 6a,b, which is because the intrinsic resistance of this material at low temperature is very large and the crossover point is outside of the testing scope. As shown in Figure 6c-f, because of some non-ideal effects [25], the crossover point at low frequency still does not exist, so it should be tangent to get the crossover point. It can be seen that as temperature increases from $100{ }^{\circ} \mathrm{C}$, the arcs gradually becomes semicircular and the extent of intercept of semicircle on the real axis decreases which means the resistance of the sample decreases with increasing temperature. The exact calculated values of resistance $\left(R_{\mathrm{s}}\right)$ and conductivity $\left(\sigma_{\mathrm{s}}\right)$ at different temperature, from the tangent curves, are listed in Table 1, which is similar to Hashimoto's research [26]. The range of resistance is from $573 \mathrm{M} \Omega\left(300{ }^{\circ} \mathrm{C}\right)$ to $228 \mathrm{~K} \Omega\left(600{ }^{\circ} \mathrm{C}\right)$, and compared with traditional perovskite ceramic, like $\mathrm{LaTiO}_{3}$, its resistance was low. This obvious decreasing of resistance is due to the increasing of thermally activated charge carriers and the existence of some additional bands in the sample [27].

Table 1. Comparison of impedance parameters' at different temperature.

\begin{tabular}{ccc}
\hline Temperature $\left({ }^{\circ} \mathbf{C}\right)$ & $\boldsymbol{R}_{\mathbf{s}}(\boldsymbol{\Omega})$ & $\boldsymbol{\sigma}_{\mathbf{s}}(\mathbf{S} / \mathbf{m})$ \\
\hline 300 & $573 \mathrm{M}$ & $9.249 \times 10^{-9}$ \\
400 & $2.84 \mathrm{M}$ & $1.866 \times 10^{-6}$ \\
500 & $550 \mathrm{~K}$ & $9.635 \times 10^{-6}$ \\
600 & $228 \mathrm{~K}$ & $2.325 \times 10^{-5}$ \\
\hline
\end{tabular}





Figure 6. Complex impedance spectra of $\mathrm{La}_{0.9} \mathrm{Sr}_{0.1} \mathrm{TiO}_{3+\delta}$ : (a) $100{ }^{\circ} \mathrm{C}$; (b) $200{ }^{\circ} \mathrm{C}$; (c) $300{ }^{\circ} \mathrm{C}$; (d) $400{ }^{\circ} \mathrm{C}$; (e) $500{ }^{\circ} \mathrm{C}$; (f) $600{ }^{\circ} \mathrm{C}$.

\subsection{Photoelectric Property}

To study its photoelectric properties is significant for us to understand more about this material and then to lay a foundation for it to apply in some related fields. In this work, the performance of LST in ultraviolet light is tested by photoconductive measurement. Figure 7 shows the bright current (red line) under ultraviolet light illumination $(395 \mathrm{~nm}, 365 \mathrm{~nm}, 294 \mathrm{~nm})$ and the dark current (black line) as a background, but no light, as functions of applied voltage in the range of $-2.0-2.0 \mathrm{~V}$. In Figure $7 \mathrm{a}$, 
when the wavelength of the incoming light is $395 \mathrm{~nm}$, the curves of the bright current and dark current are very close. This is because the photon's energy of $395 \mathrm{~nm}$ wavelength light is not enough to significantly stimulate the valence band electron. In Figure 7b,c under the light wavelength of $365 \mathrm{~nm}$ and $294 \mathrm{~nm}$, compared with the dark current the bright current increased by $50 \%$ at most. It is indicated that the photon's energy of $365 \mathrm{~nm}$ and $294 \mathrm{~nm}$ wavelength lights can stimulate a large number of valence band electron. So the increasing of carries density of LST leads to an obvious increasing of bright current. The electron of $365 \mathrm{~nm}$ light has less energy and it is closer to band gap $E_{\mathrm{g}}$ of LST. The result of photoconductive measurement under ultraviolet light illumination suggests that $365 \mathrm{~nm}$ electron already can stimulate a large number of valence band electron of LST. The band gap $E_{\mathrm{g}}$ of LST can be calculated based on this photon energy and $E_{\mathrm{g}}$ is about $3.39 \mathrm{eV}$. In addition, the band gap of LST also has been evaluated from the activation energy based on the temperature dependence of resistivity, which is about $2.6 \mathrm{eV}$, but the activation energy may be reduced by the defects [28], so the $E_{\mathrm{g}}$ of $3.39 \mathrm{eV}$ we calculated is acceptable. The value of $E_{\mathrm{g}}$ indicates that $\mathrm{La}_{0.9} \mathrm{Sr}_{0.1} \mathrm{TiO}_{3+\delta}$ is a kind of wide-band-gap semiconductor materials [29], as the typical semiconductor material $\mathrm{SrTiO}_{3}$ [30]. Wide-band-gap semiconductor materials as a kind of electronic material can have a good anti-interference ability [31]. Although LST is Mott insulator, it does not satisfy the transition conditions in our study [32,33], so LST still shows insulating properties.
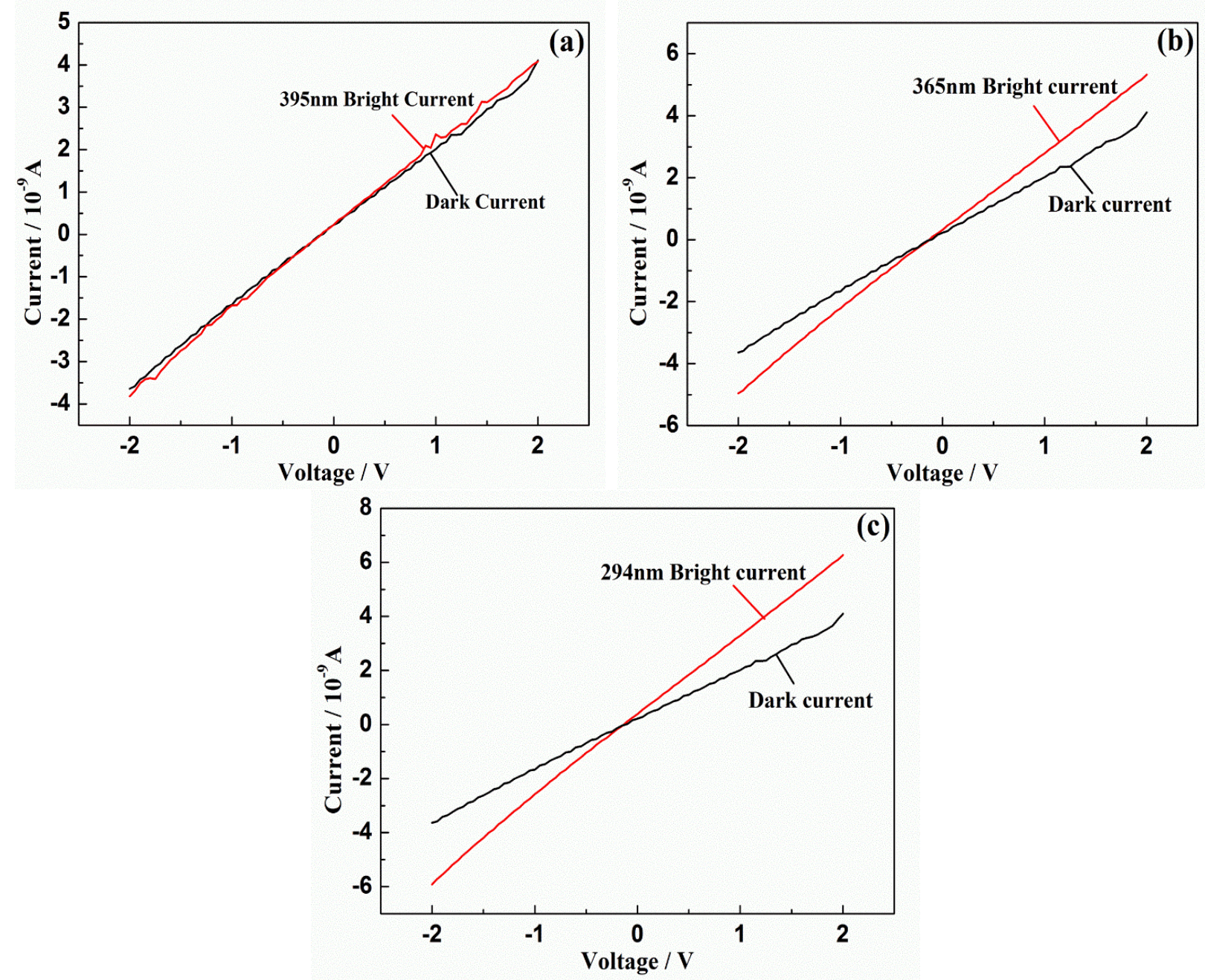

Figure 7. Photoconductivity instrument of $\mathrm{La}_{0.9} \mathrm{Sr}_{0.1} \mathrm{TiO}_{3+\delta}$ : (a) $395 \mathrm{~nm}$; (b) $365 \mathrm{~nm}$; (c) $294 \mathrm{~nm}$. 


\section{Conclusions}

The bulk material of $\mathrm{La}_{0.9} \mathrm{Sr}_{0.1} \mathrm{TiO}_{3+\delta}$ ceramic with perovskite structure was prepared by high-temperature solid-state reaction method. After sintering at $1650{ }^{\circ} \mathrm{C}$ for $8 \mathrm{~h}$, the $\mathrm{SrLa} 8 \mathrm{Ti}_{9} \mathrm{O}_{31}$ single phase was obtained. Its relative dielectric constant and dielectric loss of are stable under $350{ }^{\circ} \mathrm{C}$ especially at high frequency, well the relative dielectric constant is between 52 and 88 and dielectric loss can reach $6.5 \times 10^{-3}$. The value of conductivity was increased with rise in temperature, which suggests the existence of negative temperature coefficient of the resistance in this material. The conductivity of $\mathrm{La}_{0.9} \mathrm{Sr}_{0.1} \mathrm{TiO}_{3+\delta}$ can reach $2.325 \times 10^{-5}$ at most. The calculated band gap $(3.39 \mathrm{eV})$ of this material indicates that this kind of material belongs to wide-band-gap semiconductor materials. Its dielectric properties and forbidden bandwidth indicate it could be an electronic material.

\section{Acknowledgments}

The authors acknowledge the financial support of the "Program for New Century Excellent Talents in University" of China's Ministry of Education (NCET-11-0788), the National Natural Science Foundation of China (51302013) and "Excellent Young Teachers Program" of Beijing Institute of Technology. At last, the authors would like to acknowledge the help of Prof. Zhong.

\section{Author Contributions}

Wenzhi Li had full access to all of the data in the study and takes responsibility for the integrity of the data and the accuracy of the data analysis. Lihong Gao, Zhuang Ma, Fuchi Wang contributed their idea for this study and preparation of this manuscript.

\section{Conflicts of Interest}

The authors declare no conflict of interest.

\section{References}

1. Kageyama, K.; Saito, K.; Murase, H.; Utaki, H.; Yamamoto, T. Tunable active filters having multilayer structure using LTCC. IEEE Trans. Microw. Theory Tech. 2001, 49, 2421-2424.

2. Zhu, H.; Zhou, H.Q.; Liu, M.; Wei, P.F.; Ning, G. Low temperature sintering and properties of $\mathrm{CaO}-\mathrm{B}_{2} \mathrm{O}_{3}-\mathrm{SiO}_{2}$ system glass ceramics for LTCC applications. J. Alloy. Compd. 2009, 482, 272-275.

3. Intatha, U.; Eitssayeam, S.; Wang, J.; Tunkasiri, T. Impedance study of giant dielectric permittivity in $\mathrm{BaFe}_{0.5} \mathrm{Nb}_{0.5} \mathrm{O}_{3}$ perovskite ceramic. Curr. Appl. Phys. 2010, 10, 21-25.

4. Key, S.H.; Lee, D.W.; Jung, J.W.; Kim, B.K.; Cho, Y.S. Phase evolution and enhanced dielectric properties of $\mathrm{BaO} \cdot \mathrm{Nd}_{2} \mathrm{O}_{3} \cdot \mathrm{TiO}_{2} \cdot \mathrm{B}_{2} \mathrm{O}_{3}$. J. Alloy. Compd. 2012, 530, 40-47.

5. Fasquelle, D.; Carru, J.C.; le Gendre, L.; le Paven, C.; Pinel, J.; Chevire, F.; Tessier, F.; Marchand, R. Lanthanum titanate ceramics: Electrical characterizations in large temperature and frequency ranges. J. Eur. Ceram. Soc. 2005, 25, 2085-2088. 
6. Senz, S.; Graff, A.; Hesse, D.; Abicht, H.P. Formation of an amorphous product phase during the solid state reaction between a vitreous $\mathrm{SiO}_{2}$ thin film and a (001) $\mathrm{BaTiO}_{3}$ substrate. J. Eur. Ceram. Soc. 2000, 20, 2469-2475.

7. Ouchi, H.; Kawashima, S. Dielectric ceramics for microwave application. Jpn. J. Appl. Phys. 1985, 24, doi:10.7567/JJAPS.24S2.60.

8. Kotecki, D.E.; Baniecki, J.D.; Shen, H.; Laibowitz, R.B.; Saenger, K.L.; Lian, J.J.; Shaw, T.M.; Athavale, S.D.; Cabral, C.; Duncombe, P.R.; et al. (Ba, $\mathrm{Sr}) \mathrm{TiO}_{3}$ dielectrics for future stacked-capacitor DRAM. IBM J. Res. Develop. 1999, 43, 367-382.

9. Gao, L.H.; Ma, Z.; Wang, S.; Wang, F.C.; Yang, C. Structural and optical properties of $\mathrm{La}_{1-x} \mathrm{Sr}_{x} \mathrm{TiO}_{3+\delta}$. Materials 2014, 7, 4982-4993.

10. Gao, L.H.; Ma, Z.; Fan, Q.B. First-principle studies of the electronic structure and reflectivity of $\mathrm{LaTiO}_{3}$ and $\mathrm{Sr}$ doped $\mathrm{LaTiO}_{3}\left(\mathrm{La}_{1-x} \mathrm{Sr}_{x} \mathrm{TiO}_{3}\right)$. J. Electroceram. 2011, 27, 114-119.

11. Takamura, H.; Enomotol, K.; Kamegawa, A.; Okada, M. Electrical conductivity of layered compounds in $\mathrm{SrO}-\mathrm{La}_{2} \mathrm{O}_{3}-\mathrm{TiO}_{2}$ systems prepared by the Pechini process. Solid. State Ion. 2002, 154, 581-588.

12. Moos, R.; Gnudi, A.; Hardtl, K.H. Thermopower of $\mathrm{Sr}_{1-x} \mathrm{La}_{x} \mathrm{TiO}_{3}$ ceramics. J. Appl. Phys. 1995, $78,5042-5047$.

13. Banno, H. Effects of shape and volume fraction of closed pores on dielectric, elastic, and electromechanical properties of dielectric and piezoelectric ceramics: A theoretical approach. Am. Ceram. Soc. Bull. 1987, 66, 1332-1337.

14. Das, P.R.; Biswal, L.; Behera, B.; Choudhary, R.N.P. Structural and electrical properties of $\mathrm{Na}_{2} \mathrm{~Pb}_{2} \mathrm{Eu}_{2} \mathrm{~W}_{2} \mathrm{Ti}_{4} \mathrm{X}_{4} \mathrm{O}_{30}(\mathrm{X}=\mathrm{Nb}, \mathrm{Ta})$ ferroelectric ceramics. Mater. Res. Bull. 2009, 44, 1214-1218.

15. Choi, M.; Posadas, A.B.; Rodriguez, C.A.; O’Hara, A.; Seinige, H.; Kellock, A.J.; Frank, M.M.; Tsoi, M.; Zollner, S.; Narayanan, V.; et al. Structural, optical, and electrical properties of strained La-doped $\mathrm{SrTiO}_{3}$ films. J. Appl. Phys. 2014, 116, doi:10.1063/1.4891225.

16. Pati, B.; Sutar, B.C.; Parida, B.N.; Das, P.R.; Choudhary, R.N.P. Dielectric and impedance spectroscopy of barium orthovanadate ceramics. J. Mater. Sci. Mater. Electron. 2013, 24, 1608-1616.

17. Abhijit, P.; Amitabha, B. Structural, dielectric and electrical properties of lithium silicate ceramics: A comparative study. J. Mater. Sci. Mater. Electron. 2013, 24, 1855-1862.

18. Khatri, P.; Behera, B.; Srinivas, V.; Choudhary, R.N.P. Structural and dielectric properties of $\mathrm{Ba}_{3} \mathrm{~V}_{2} \mathrm{O}_{8}$ ceramics. Curr. Appl. Phys. 2009, 9, 515-519.

19. Bhardwaj, S.; Pail, J.; Chand, S. Oxygen vacancy induced dielectric relaxation studies in $\mathrm{Bi}_{-x} \mathrm{La}_{x} \mathrm{Ti}_{3} \mathrm{O}_{12}(x=0.0,0.3,0.7,1.0)$ ceramics. J. Mater. Sci. Mater. Electron. 2014, 25, 4568-4576.

20. Sutar, B.C.; Choudhary, R.N.P.; Das, P.R. Dielectric and impedance spectroscopy of $\mathrm{Sr}\left(\mathrm{Bi} 0.5 \mathrm{Nb}_{0.5}\right) \mathrm{O}_{3}$ ceramics. Ceram. Int. 2014, 40, 7791-7798.

21. Donald, A.N. Semiconductor Physics and Devices Basic Principles; Publishing House of Electronics Industry: Beijing, China, 2003.

22. White, M.A. Physical Properties of Materials; CRC Press: Boca Raton, FL, USA, 2011.

23. Jonscher, A.K. The "universal" dielectric response. Nature 1977, 267, 673-679.

24. Mcdonald, J.R. Impedance Spectroscopy: Emphasizing Solid Materials and Systems; Wiley: New York, NY, USA, 1987. 
25. Burg, G.J.; Vandeneeden, A.L.G.; Sluytersrehbach, M. The analysis of electrode impedances complicated by the presence of a constant phase element. J. Electroanal. Chem. Interfacial Electrochem. 1984, 176, 275-295.

26. Hashimoto, S.; Kindermann, L.; Poulsen, F.M.; Mogensen, M. A study on the structural and electrical properties of lanthanum-doped strontium titanate prepared in air. J. Alloy. Compd. 2005, 397, 245-249.

27. Moos, R.; Schöllhammer, S.; Härdtl, K.H. Electron mobility of $\mathrm{Sr}_{1-x} \mathrm{La}_{x} \mathrm{TiO}_{3}$ ceramics between $600{ }^{\circ} \mathrm{C}$ and $1300{ }^{\circ} \mathrm{C}$. Appl. Phys. A 1997, 65, 291-294.

28. Brinzari, V.; Korotcenkov, G.; Ivanov, M.; Nehasil, V.; Matolin, V.; Mašek, K.; Kamei, M. Valence band and band gap photoemission study of ( $\left.\begin{array}{lll}1 & 1 & 1\end{array}\right) \mathrm{In}_{2} \mathrm{O}_{3}$ epitaxial films under interactions with oxygen, water and carbon monoxide. Surf. Sci. 2007, 601, 5585-5594.

29. Chakrabortya, S.; Sadhukhana, M.; Chaudhuria, B.K.; Mori, H.; Sakata, H. Frequency dependent electrical conductivity and dielectric relaxation behavior in amorphous $\left(90 \mathrm{~V}_{2} \mathrm{O}_{5}-10 \mathrm{Bi}_{2} \mathrm{O}_{3}\right)$ oxide semiconductors doped with $\mathrm{SrTiO}_{3}$. Mater. Chem. Phys. 1997, 50, 219-226.

30. Takahashi, K.; Yoshikawa, A.; Sandhu, A. Wide Bandgap Semiconductors; Springer: New York, NY, USA, 2007.

31. Trivedi, M.; Shenai, K. Performance evaluation of high-power wide band-gap semiconductor rectifiers. J. Appl. Phys. 1999, 85, 6889-6897.

32. Mott, N.F. The Metal-Insulator Transition; Taylor and Francis: London, UK, 1974.

33. Vilquin, B.; Kanki, T.; Yanagida, T.; Tanaka, H.; Kawai, T. Control of $p$-type conductivity in Sr doped $\mathrm{LaTiO}_{3}$ thin films. Solid State Commun. 2005, 136, 328-332.

(C) 2015 by the authors; licensee MDPI, Basel, Switzerland. This article is an open access article distributed under the terms and conditions of the Creative Commons Attribution license (http://creativecommons.org/licenses/by/4.0/). 